\title{
PERSPECTIVE
}

\section{Global Alliance against Chronic Respiratory}

\section{Diseases}

\author{
J. Bousquet*, R. Dahl ${ }^{\#}$ and N. Khaltaev
}

ABSTRACT: Hundreds of millions of people of all ages suffer from chronic respiratory diseases which include asthma and respiratory allergies, chronic obstructive pulmonary disease, occupational lung diseases and pulmonary hypertension. More than $\mathbf{5 0 0}$ million patients live in developing countries or in deprived populations. Chronic respiratory diseases are increasing in prevalence. Although the cost of inaction is clear and unacceptable, chronic respiratory diseases and their risk factors receive insufficient attention from the healthcare community, government officials, media, patients and families. The Fifty-Third World Health Assembly recognised the enormous human suffering caused by chronic diseases and requested the World Health Organization (WHO) Director General to give priority to the prevention and control of chronic diseases, with special emphasis on developing countries. This led to the formation of the WHO Global Alliance against Chronic Respiratory Diseases (GARD). GARD is a voluntary alliance of organisations, institutions and agencies working towards a common vision to improve global lung health according to local needs. GARD is developed in a stepwise approach using the following three planning steps: estimate population need and advocate action; formulate and adopt policy; and identify policy implementation steps.

KEYWORDS: Asthma, chronic obstructive pulmonary disease, chronic respiratory diseases, World Health Organization

W orld health is generally improving, with fewer people dying from infectious diseases and, therefore, in many cases, living long enough to develop chronic diseases [1].

From a projected total of 58 million deaths from all causes in 2005, it is estimated that chronic diseases will account for 35 million deaths [2], which is double the number of deaths from all infectious diseases (including HIV/AIDS, tuberculosis and malaria), maternal and perinatal conditions, and nutritional deficiencies combined (fig. 1).

For the next 10-20 yrs, communicable diseases will remain the predominant health problem for populations of low-income countries. However, an epidemic of chronic diseases is expected to occur in the future in all countries, including developing countries [3-5].

This article is co-published in the March issue (volume 63, issue 3) of Allergy (Allergy 2007; DOI: 10.1111/j.1398-9995. 2006.01307.x).

\section{CHRONIC RESPIRATORY DISEASES AND THEIR BURDEN}

Chronic respiratory diseases (CRD), i.e. chronic diseases of the airways and the other structures of the lungs, represent a wide array of serious diseases. Common CRD are listed in table 1. Preventable CRD include asthma and respiratory allergies, chronic obstructive pulmonary disease (COPD), occupational lung diseases and pulmonary hypertension. CRD constitute a serious public health problem in all countries throughout the world, in particular in developing countries and in deprived populations.

Throughout the world, millions of people of all ages are affected by preventable CRD (table 2). More than $50 \%$ of them live in developing countries or deprived populations. The prevalence of preventable CRD is increasing everywhere and in particular in children and elderly people.

The burden of preventable CRD has major adverse effects on the quality of life and disability of affected individuals. CRD cause premature deaths and create large adverse and under-appreciated

\section{AFFILIATIONS}

*Hôpital Arnaude de Villeneuve, CHU Montpellier, Montpellier, France

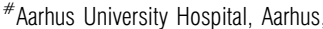
Denmark,

"World Health Organization, Geneva, Switzerland.

CORRESPONDENCE

N. Khaltaev

World Health Organization

20 Avenue Appia

CH-1211 Geneva 27

Switzerland

Fax: 41227914766

E-mail: khaltaevn@who.ch

Received:

October 252006

Accepted after revision:

November 102006

STATEMENT OF INTEREST

None declared.

European Respiratory Journal Print ISSN 0903-1936 Online ISSN 1399-3003 


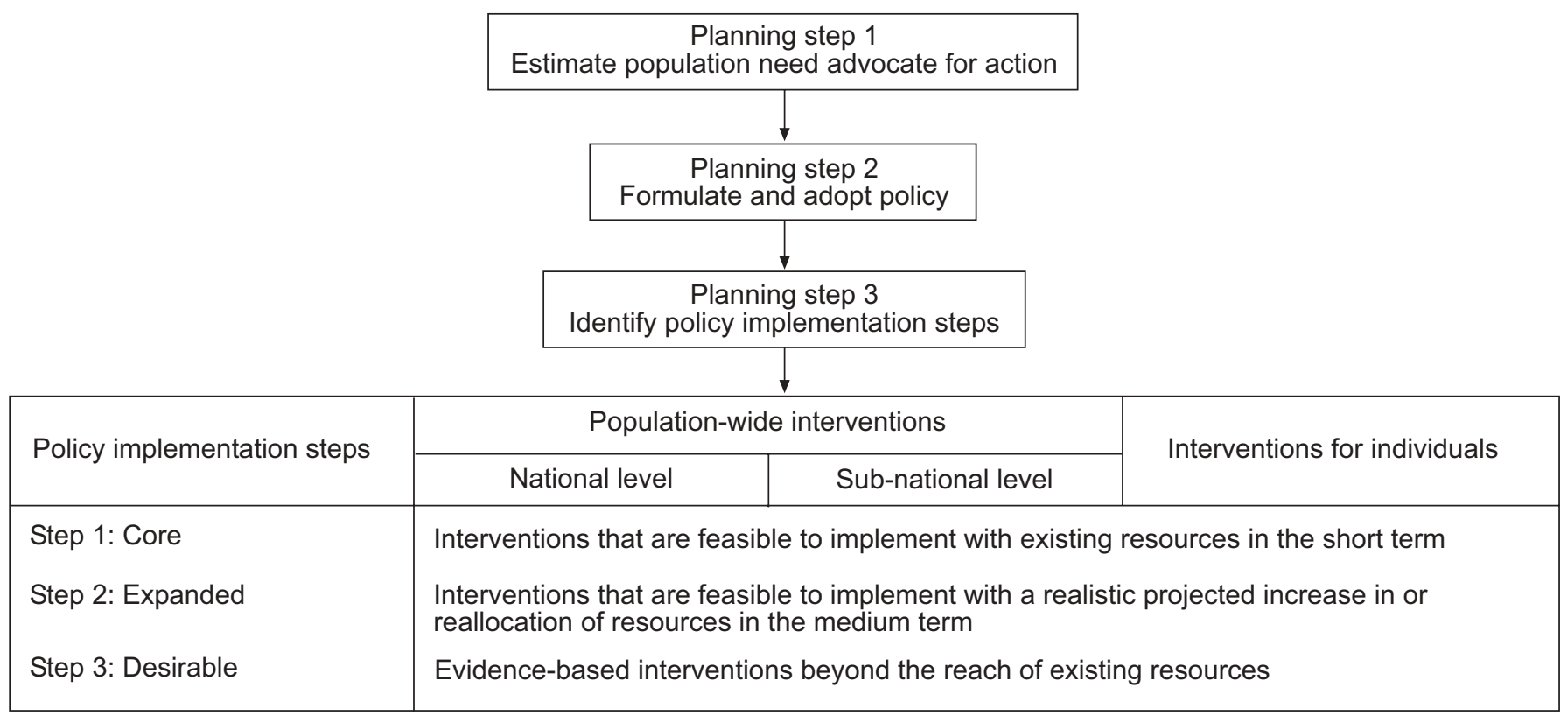

FIGURE 1. The stepwise framework.

economic effects on families, communities and societies in general. The World Health Organization (WHO) and the World Bank have estimated that 4.6 million people with CRD will die prematurely in 2005, and have projected that the global burden of CRD will increase considerably in the future. However, many preventable CRD can be controlled with adequate management in both developed [25] and developing countries [26, 27], as well as in deprived populations $[28,29]$. These interventions were found to be cost-effective.

Many risk factors for preventable CRD have been identified and efficient preventive measures proposed (table 3). Tobacco smoking in both developed and developing countries, indoor air pollution (particularly in developing countries), allergens, occupational agents, some diseases, such as schistosomiasis or sickle-cell disease, and living at altitude all cause preventable CRD. Prevention of these risk factors will have a significant impact on morbidity and mortality.

However, preventable CRD and their risk factors receive insufficient attention from the healthcare community, government officials, patients and families, as well as the media. Preventable CRD are under-recognised, under-diagnosed, under-treated and insufficiently prevented.

The 53rd World Health Assembly (WHA) recognised the enormous human suffering caused by chronic diseases and

\section{TABLE 1 Common chronic respiratory diseases}

Diseases

ICD-10

Asthma

Bronchiectasis

Chronic obstructive lung disease including COPD, bronchitis and emphysema

Chronic rhinosinusitis

Hypersensitivity pneumonitis

Lung cancer and neoplasms of respiratory and intrathoracic organs

Lung fibrosis

Chronic pleural diseases

Pneumoconiosis

Pulmonary eosinophilia

Pulmonary heart disease and diseases of pulmonary circulation including pulmonary embolism, pulmonary hypertension and cor pulmonale

Rhinitis

Sarcoidosis

Sleep apnoea syndrome
$\mathrm{J} 45-46$

A15-16" , J44, J47, Q32-33

J40-47

J32-33

J66-67

C30-39

A15-16", J62-63, J70, P27

C38, C45, D38, J61, J92

A15-16" ${ }^{\#}$, J60-65

J82

126-28

J30-31, J45

D86

G47

ICD: international classification of disease. COPD: chronic obstructive pulmonary disease. ${ }^{*}$ : In patients with tuberculosis. Data taken from [6]. 


\begin{tabular}{lccc} 
TABLE 2 & $\begin{array}{l}\text { Estimates for the prevalence of preventable } \\
\text { chronic respiratory diseases (CRD) }\end{array}$ \\
& Year of estimation & Prevalence & [Ref.] \\
\hline CRD & 2004 & 300 million & {$[7]$} \\
\hline $\begin{array}{l}\text { Asthma } \\
\text { COPD }\end{array}$ & 2000 & 80 million & {$[8]$} \\
$\begin{array}{l}\text { Allergic rhinitis } \\
\text { Other CRD } \\
\text { Sleep apnoea } \\
\text { syndrome }\end{array}$ & 2006 & 400 million & {$[9-13]$} \\
\hline & 2006 & $>50$ million & {$[8,14-20]$} \\
COPD: chronic obstructive pulmonary disease. & $>100$ million & {$[21-24]$} \\
\end{tabular}

CRD and requested the WHO Director General to give priority to the prevention and control of CRD, with special emphasis on developing countries and other deprived populations to coordinate, in collaboration with the international community, global partnerships and alliances for resource mobilisation, advocacy, capacity building and collaborative research. In order to develop a comprehensive approach for the surveillance, diagnosis, prevention and control of CRD, the WHO organised four consultation meetings, which led to the formation of the WHO Global Alliance against Chronic Respiratory Diseases (GARD) [35-39].

\section{GARD STRATEGIC FRAMEWORK}

GARD is a voluntary alliance of organisations, institutions and agencies working towards a common vision to improve global lung health according to the local needs. The vision of GARD is a world where all people can breathe freely: free breath for all. GARD's mission is to develop an enabling environment for sustainable and appropriate action at individual, community, national and global levels. The goal of GARD is to reduce the global CRD burden.

\section{Objectives}

GARD aims to: 1) develop a standard way of obtaining relevant data on CRD and risk factors; 2) encourage countries to implement health promotion and CRD prevention policies; and 3) make recommendations of simple and affordable strategies for CRD management.

Health priorities, geographic variability in risk factors and the prevalence of different forms of CRD, along with the diversity

\section{TABLE 3 Major risk factors for chronic respiratory diseases}

Tobacco smoking is the major threat in both developed and developing countries [30]

Environmental tobacco smoke is always more harmful [31]

Indoor air pollutants, particularly biomass fuels, are the unrecognised killers in developing countries [8, 32]

Outdoor air pollutants, a global vision for reduction [33]

Allergens, not only in developed countries

Occupational agents are everywhere but particularly in developing countries

[34]

Diet and nutrition are probably important

Post-infectious CRD also count of national healthcare service systems and variations in the availability and affordability of treatments all mean that any recommendations should be adapted to ensure appropriateness in the community in which they are applied.

\section{Approach}

GARD is dedicated to an integrated approach to CRD, which looks at synergies between chronic diseases and proposes a stepwise and integrated programme of prevention and control of preventable CRD and respiratory allergies, into account taking comorbidities.

GARD also focuses specifically on the needs of developing countries and deprived populations, and fosters countryspecific initiatives appropriate to local needs.

\section{Added value}

GARD will improve the coordination between the existing governmental and nongovernmental programmes to avoid duplication of efforts and wasting of resources. Increased human and financial resources, as well as technical expertise, will be effectively distributed according to the comparative advantage of each participant organisation towards the GARD vision.

\section{SPECIFIC OBJECTIVES DIFFER DEPENDING ON COUNTRY RISK FACTORS, CRD, PRIORITIES AND HEALTHCARE SYSTEMS Developing countries}

The emphasis on the needs of developing countries is appropriate considering that most CRD occur in these countries, with infectious diseases (including HIV/AIDS) adding to the burden of CRD morbidity. In many developing countries, the focus of healthcare systems is on communicable diseases and injuries. Infrastructure for the diagnosis and management of CRD is either not available or is viewed as low priority on any public-health agenda.

Data on the CRD risk factors, burden and surveillance are scarce or unavailable in most developing countries. Consequently, the true burden of CRD on health services and society is not appreciated; strategies for the prevention and health promotion of CRD are often absent or rudimentary; and exposure to risk factors for CRD, including indoor air pollution, the use of solid biomass fuels and smoking, is high.

In developing countries, surveillance systems and diagnostic services for work-related CRD are often poorly developed, and the true burden of occupational lung disease largely unknown.

Asthma is mostly under-diagnosed and under-treated (in particular in children), causing a high morbidity and a significant mortality. In addition, the exact burden of COPD is unknown but likely to be (very) high, and the treatment emphasis for conditions like asthma and COPD is based upon the treatment of exacerbations instead of chronic care and prevention of exacerbations.

In some countries, additional risk factors such as altitude, parasitosis and sickle cell disease result in unique forms of CRD.

In the majority of developing countries, diagnostic tests like spirometry that are required for the diagnosis and assessment 
of severity of CRD are not readily available, resulting in incorrect assessment and under-diagnosis of CRD; additionally, essential drugs for the treatment of CRD are not available and/or affordable in a large proportion of developing countries.

Programmes for educating healthcare professionals in the care and management of patients with CRD require strengthening in developing countries, and public awareness of CRD should be increased.

\section{Developed countries}

In developed countries, CRD are usually independent from communicable diseases and there are structures for fighting the diseases. A few successful national programmes against CRD exist. However, they are not comprehensive (e.g. asthma or COPD plans), they are fragmented, need to be expanded and integrated within a single action plan and require more coordination. Moreover, CRD are rarely on the public-health agenda. Generally, data on the CRD risk factors, burden and surveillance are fragmented and often incomplete, and awareness of CRD is largely insufficient.

Prevention and health promotion for CRD is also largely insufficient. Although many risk factors predisposing to CRD are preventable, policies and legislations are still inadequate throughout the world. The Framework Convention on Tobacco Control has become an international law but there are still many countries that have yet to ratify it. As a result: 1) asthma is under-diagnosed and not optimally controlled in many patients; 2) COPD is largely under-diagnosed, under-treated and largely induced by smoking; and 3) COPD is not regarded as a systemic disease nor assessed as part of a chronic systemic disease which often includes cardiovascular and metabolic disorders.

Work-related CRD should be better identified, diagnosed and prevented, and it should be recognised that in some countries there may be additional CRD associated with altitude.

With regard to the identification and treatment of patients with CRD, lung function testing is available in specialist practices and, in some countries, in primary care, while drugs are usually available but are not always affordable.

\section{THE STEPWISE FRAMEWORK OF THE GARD ACTION PLAN}

GARD is being developed in a stepwise approach with shortterm (step 1), medium-term (step 2) and long-term (step 3) objectives and action-plans. Each step will be associated with measurable outcomes and deliverables (figs 1 and 2).

Step 1 will involve the compilation of a background document containing an assessment of the needs and the objectives and proposed plan of action for GARD. The document will record and evaluate potential activities that might be used by national coordinators to build a country-based GARD action plan. National coordinators in developing countries will usually be public-health professionals within health services or associated with nongovernmental organisations.

During step 2, the implementation in several countries of integrated GARD-endorsed action plans for the prevention, diagnosis and management of CRD will be promoted. This will

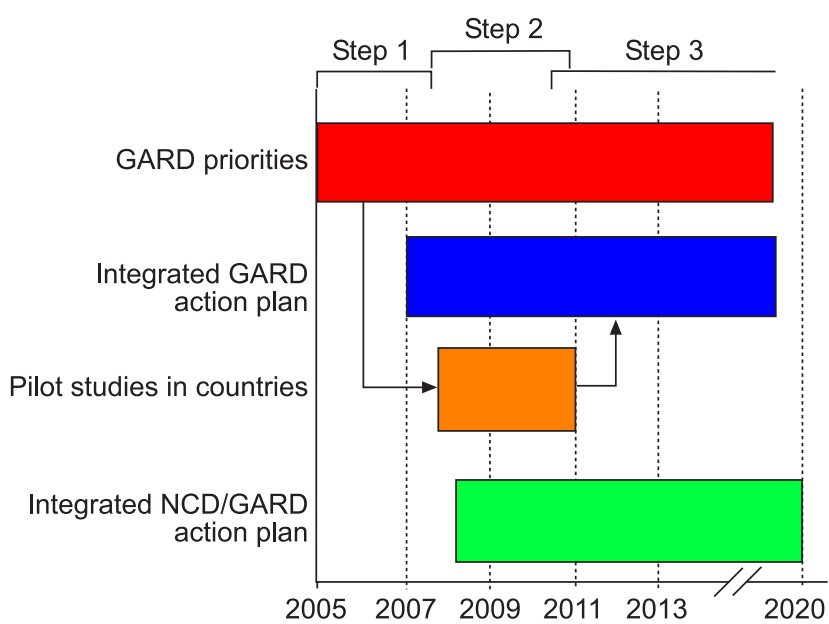

FIGURE 2. The Global Alliance against Chronic Respiratory Diseases (GARD) stepwise approach. NCD: noncommunicable disease.

involve pilot demonstration studies of programmes developed by local experts and stakeholders in each country, relevant to the needs, resources and practice setting of that country. It is due to be completed by mid 2006 to the end of 2008 .

During step 3, the GARD action plans developed during step 2 will be collated and distributed to as many countries as possible. This activity will be monitored by the information gathered during surveillance activities (step 1) as well as by the materials developed and experience gained during step 2 . The emphasis will be placed on the following issues: 1) providing guidance, technical support and assistance with sourcing of funds for implementation of programmes for improving the prevention, diagnosis and management of CRD; 2) access to essential diagnostics and drugs; and 3) education for healthcare workers in these activities.

\section{PLANNING STEP 1: ESTIMATE POPULATION NEED AND ADVOCATE FOR ACTION}

In total, three planning steps will be carried out by six working groups (WGs).

\section{WG-1: Burden, risk factors and surveillance of CRD and respiratory allergies}

In all countries, the prevalence and incidence of CRD are under-investigated. There is a need for epidemiological studies with questionnaires and simple spirometry to properly estimate the CRD burden. Existing WHO databases should be integrated with the CRD morbidity rate (and any other risk factor) data. This WG will develop a standardised process to obtain data on CRD risk factors, disease burden, trends, quality and affordability of care and the economic burden, all of which can then be compared between all countries (developed and developing) to define strategies for policy makers.

\section{WG-2: Advocacy for CRD}

Although the cost of inaction is clear and unacceptable, CRD and its risk factors receive insufficient attention from the healthcare community, government officials, media, patients and families. There is a need to elevate CRD on the health 
agenda of key policy makers. All stakeholders should be involved to increase awareness on CRD. The ultimate goal of dissemination is to provide evidence that the burden of CRD can be reduced. Therefore, it is essential to raise awareness of CRD among all stakeholders and to make CRD a public health priority in all countries.

\section{PLANNING STEP 2: FORMULATE AND ADOPT POLICY}

In all countries, a national policy and planning framework is essential to allocate chronic diseases appropriate priority and to ensure resources are organised efficiently [40]. GARD will provide the basis for action in the next $10 \mathrm{yrs}$. It is accompanied by plans and programmes for implementation of the policy. Some countries already have national asthma or COPD plans which have been found to be cost-effective [41].

\section{WG-3: Health promotion and prevention of CRD and respiratory allergies}

Everyone has the right to live and work in a clean environment. Environmental exposure to an unhealthy environment causes severe and debilitating COPD, asthma, cardiovascular diseases and cancer. Complete elimination of the risk factor is the only way to remove the risk. These messages apply equally to tobacco smoking, indoor and outdoor air pollutants, occupational exposure and allergens. WG-3 will encourage countries to implement policies in order to reduce the burden of tobacco smoke, indoor and outdoor pollution, occupational hazards and other risk factors relevant to CRD.

\section{WG-4: Diagnosis of CRD and respiratory allergies}

In all countries CRD are under-diagnosed. There is a need for early CRD diagnosis in order to reduce severe diseases and disability. Low-cost, effective spirometry and allergy tests are needed. GARD will make recommendations for providing simple and affordable diagnostic tools for CRD and respiratory allergies using approaches adapted to different health needs, services, and resources as well as proper training of health professionals in their use.

\section{WG-5: Control of CRD and allergy and drug accessibility}

GARD action plans should be tailored to each country's needs, priorities, health services and resources (fig. 3).

In areas with a high burden of communicable diseases and a functioning primary healthcare service, an integrated approach to the prevention, diagnosis and management is recommended. Models like the WHO-Practical Approach to Lung Health (PAL) will be promoted [42]. In areas with a high prevalence of HIV infection, models like PAL in South Africa Plus will be promoted [26].

Models of prevention and care for CRD in middle- and highincome countries will use a different model. Disease-specific approaches may be more relevant. They will target asthma, rhinitis, COPD and occupational lung diseases. Approaches will be developed from available management plans and international guidelines according to specific country needs. Of particular interest is the control of occupational CRD and pulmonary hypertension which have not received enough attention worldwide.

The key aspects of GARD action plans will be as follows. 1) To ensure the availability of drugs for patients with CRD in each treatment setting. Most asthmatics live in developing countries and in deprived areas; however, access to essential drugs is
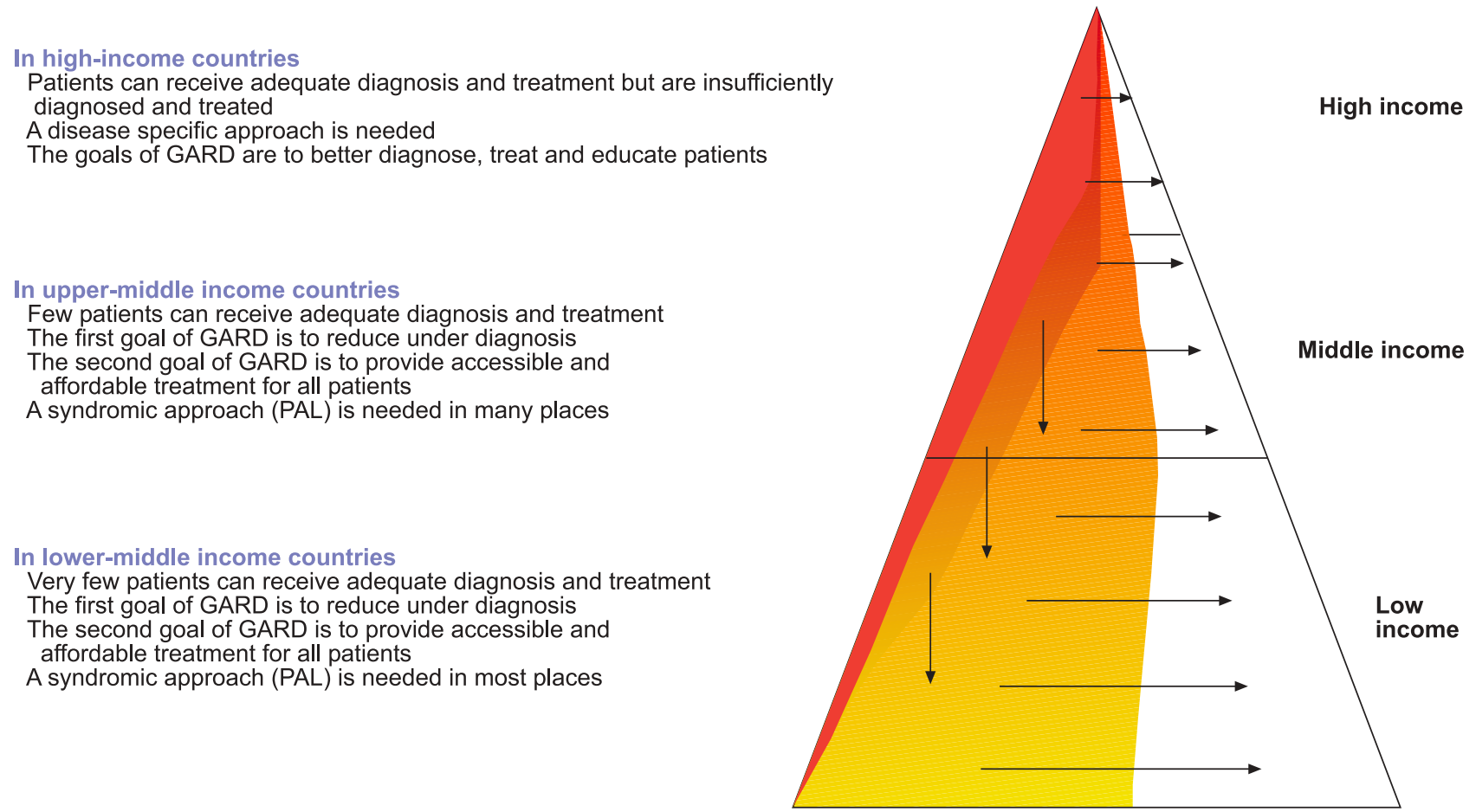

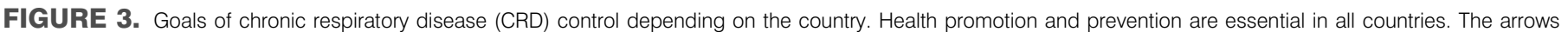

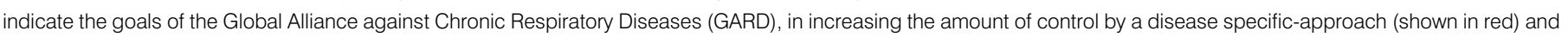

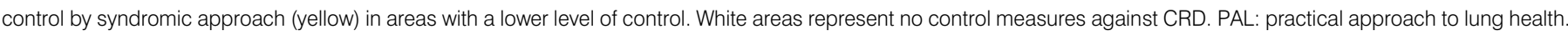


limited in these regions. The Asthma Drug Facility recently proposed by the Union [43] will be used by GARD. 2) To assist in knowledge translation strategies for the training of healthcare workers in the management of CRD.

\section{WG-6: Paediatric CRD and respiratory allergies}

CRD in children should be considered separately, but, as for adults, GARD should consider low-, middle- and high-income settings and make short-, medium- and long-range goals.

\section{PLANNING STEP 3: IDENTIFY POLICY IMPLEMENTATION STEPS}

The GARD action plan needs to be implemented at national and/or regional levels. Health priorities, geographic variability in risk factors and CRD, the diversity of national healthcare service systems and variations in the availability and affordability of treatments all require that any recommendation should be adapted locally to ensure their appropriateness in the community in which they are applied. Implementation plans should include all stakeholders and be under the responsibility of the Ministry of Health. The policy implementation process will follow the recommendations of the "Preventing Chronic Disease" report [1] with three main planning steps as follows. Step 1 (Core): interventions that are feasible to implement with existing resources in the short term. Step 2 (Expanded): interventions that are possible to implement with a realistically projected increase in, or reallocation of, resources in the medium term. Step 3 (Desirable): evidencebased interventions which are beyond the reach of existing resources.

\section{ACKNOWLEDGEMENTS}

The GARD secretariat, in the WHO Headquarters in Geneva, is responsible for the management, evaluation and monitoring of GARD initiatives.

The committee members of GARD are as follows: J. Bousquet, GARD Chair (Montpellier, France); R. Dahl, GARD Co-chair (Aarhus, Denmark); N. Khaltaev, WHO coordinator of GARD (Geneva, Switzerland). The following are members of the GARD Planning Group, Working Group Chairs and individual experts: C. Baena-Cagnani (Córdoba, Argentina); P. Van Cauwenberge (Ghent, Belgium); J.L. Malo (Québec, QC) and F.E. Simons (Winnipeg, MB; both Canada); N. Zhong (Guangzhou, China); E. Valovirta (Turku, Finland); N. AïtKhaled (Paris) and M. Humbert (Clamart, both France); M. Boland (Dublin, Ireland); G.W. Canonica (Genoa), L. Fabbri (Modena) and G. Viegi (Pisa; all Italy); Y. Fukuchi and R. Pawankar (both Tokyo, Japan); E. Bateman (Cape Town, South Africa); A. Turnbull (Lausanne, Switzerland); K. Rabe (Leiden) and C. Van Weel (Nijmegen; both the Netherlands); A. Custovic (Manchester, UK); S. Buist (Portland, OR), L Grouse (Seattle, WA), C. Lenfant (Gaithersburg, MD) and S. Wenzel (Denver, CO; all USA). The WHO staff members are: E. Mantzouranis (Heraklion, Greece); P. Matricardi (Rome) and E. Minelli (Milan; both Italy); S. Ottmani (Rabat, Morocco). The individual experts are: H. Douagi (Algiers, Algeria); C. Luna (Buenos Aries, Argentina); G. Joos (Ghent, Belgium); P. Camargos (Belo Horizonte) and A. Cruz (Salvador; both Brazil); T. Popov (Sofia, Bulgaria); S. Ouedraogo (Quagadougou, Burkina Faso); P. O'Byrne (Hamilton, ON, Canada); Y.Z. Chen (Beijing), J-T. Lin (Beijing) and Y-J. Xu (Wuhan; all China); B. Hellquist (Aarhus,
Denmark); T. Haahtela (Helsinki) and M. Nieminen (Tampere; both Finland); A. Gamkrelidze (Tbilisi, Georgia); W. McNicholas (Dublin, Ireland); S. Bonini (Naples, Italy); S. Makino (Tokyo, Japan); S. Mavale-Manuel (Maputo, Mozambique); O. Yusuf (Islamabad, Pakistan); K. Roszkowski (Warsaw, Poland); J. Rosado-Pinto (Lisbon, Portugal); A. Chuchalin (Moscow, Russia); Y.-Y. Kim (Seoul, South Korea); M. Yousser (Latakia, Syria); W. Fokkens (Amsterdam, the Netherlands); A. Ben Kheder (Tunis, Tunisia); A. Kocabas (Adana, Turkey); P. Calverley (Liverpool, UK); S. Hurd (Gaithersburg, MD), J. Kiley (Bethesda, MD), F. Martinez (Tucson, AZ) and A. Togias (Baltimore, MD; all USA).

\section{REFERENCES}

1 World Health Organization. Preventing chronic diseases: a vital investment. WHO global report, 2005. www.who. int/chp/chronic_disease_report/full_report.pdf. Date last accessed: December 2006.

2 Strong K, Mathers C, Leeder S, Beaglehole R. Preventing chronic diseases: how many lives can we save? Lancet 2005; 366: 1578-1582.

3 Lee J. Global health improvement and WHO: shaping the future. Lancet 2003; 362: 2083-2088.

4 Srinath Reddy K, Shah B, Varghese C, Ramadoss A. Responding to the threat of chronic diseases in India. Lancet 2005; 366: 1744-1749.

5 Wang L, Kong L, Wu F, Bai Y, Burton R. Preventing chronic diseases in China. Lancet 2005; 366: 1821-1824.

6 World Health Organization. International Statistical Classification of Diseases and Related Health Problems. 10th Revision Version for 2003. Geneva, World Health Organization Press, 2003.

7 Masoli M, Fabian D, Holt S, Beasley R, the Global Initiative for Asthma (GINA) Program. The global burden of asthma: executive summary of the GINA Dissemination Committee report. Allergy 2004; 59: 469-478.

8 The World Health Organization. Preventing risks and taking action. In: The World Health Report. Geneva, World Health Organization Press, 2002; p. 167.

9 Worldwide variation in prevalence of symptoms of asthma, allergic rhinoconjunctivitis, and atopic eczema: ISAAC. The International Study of Asthma and Allergies in Childhood (ISAAC) Steering Committee. Lancet 1998; 351: 1225-1232.

10 Janson C, Anto J, Burney P, et al. The European Community Respiratory Health Survey: what are the main results so far? European Community Respiratory Health Survey II. Eur Respir J 2001; 18: 598-611.

11 Bauchau V, Durham SR. Epidemiological characterization of the intermittent and persistent types of allergic rhinitis. Allergy 2005; 60: 350-353.

12 Bauchau V, Durham SR. Prevalence and rate of diagnosis of allergic rhinitis in Europe. Eur Respir J 2004; 24: 758-764.

13 Pearce N, Sunyer J, Cheng S, et al. Comparison of asthma prevalence in the ISAAC and the ECRHS. ISAAC Steering Committee and the European Community Respiratory Health Survey. International Study of Asthma and Allergies in Childhood. Eur Respir J 2000; 16: 420-426.

14 Ross MH, Murray J. Occupational respiratory disease in mining. Occup Med (Lond) 2004; 54: 304-310. 
15 Wang XR, Christiani DC. Occupational lung disease in China. Int J Occup Environ Health 2003; 9: 320-325.

16 Barbosa MM, Lamounier JA, Oliveira EC, et al. Pulmonary hypertension in schistosomiasis mansoni. Trans $R$ Soc Trop Med Hyg 1996; 90: 663-665.

17 Powars DR, Chan LS, Hiti A, Ramicone E, Johnson C. Outcome of sickle cell anemia: a 4-decade observational study of 1056 patients. Medicine (Baltimore) 2005; 84: 363-376.

18 Machado RF, Gladwin MT. Chronic sickle cell lung disease: new insights into the diagnosis, pathogenesis and treatment of pulmonary hypertension. Br J Haematol 2005; 129: 449-464.

19 Aldashev AA, Sarybaev AS, Sydykov AS, et al. Characterization of high-altitude pulmonary hypertension in the Kyrgyz: association with angiotensin-converting enzyme genotype. Am J Respir Crit Care Med 2002; 166 1396-1402.

20 Ge RL, Helun G. Current concept of chronic mountain sickness: pulmonary hypertension-related high-altitude heart disease. Wilderness Environ Med 2001; 12: 190-194.

21 Gislason T, Almqvist M, Eriksson G, Taube A, Boman G. Prevalence of sleep apnea syndrome among Swedish men an epidemiological study. J Clin Epidemiol 1988; 41: 571-576.

22 Enright PL, Newman AB, Wahl PW, Manolio TA, Haponik EF, Boyle PJ. Prevalence and correlates of snoring and observed apneas in 5,201 older adults. Sleep 1996; 19: 531-538.

23 Ohayon MM, Guilleminault C, Priest RG, Caulet M. Snoring and breathing pauses during sleep: telephone interview survey of a United Kingdom population sample. BMJ 1997; 314: 860-863.

24 Larsson LG, Lindberg A, Franklin KA, Lundback B. Gender differences in symptoms related to sleep apnea in a general population and in relation to referral to sleep clinic. Chest 2003; 124: 204-211.

25 Haahtela T, Tuomisto LE, Pietinalho A, et al. A 10 year asthma programme in Finland: major change for the better. Thorax 2006; 61: 663-670.

26 Fairall LR, Zwarenstein M, Bateman ED, et al. Effect of educational outreach to nurses on tuberculosis case detection and primary care of respiratory illness: pragmatic cluster randomised controlled trial. BMJ 2005; 331: 750-754.

27 Fischer GB, Camargos PA, Mocelin HT. The burden of asthma in children: a Latin American perspective. Paediatr Respir Rev 2005; 6: 8-13.

28 Evans R 3rd, Gergen PJ, Mitchell H, et al. A randomized clinical trial to reduce asthma morbidity among inner-city children: results of the National Cooperative Inner-City Asthma Study. J Pediatr 1999; 135: 332-338.

29 Cloutier MM, Hall CB, Wakefield DB, Bailit H. Use of asthma guidelines by primary care providers to reduce hospitalizations and emergency department visits in poor, minority, urban children. J Pediatr 2005; 146: 591-597.
30 Ezzati M, Lopez AD. Estimates of global mortality attributable to smoking in 2000. Lancet 2003; 362: 847-852.

31 Janson C. The effect of passive smoking on respiratory health in children and adults. Int J Tuberc Lung Dis 2004; 8: 510-516.

32 Bruce N, Perez-Padilla R, Albalak R. Indoor air pollution in developing countries: a major environmental and public health challenge. Bull World Health Organ 2000; 78: 1078-1092.

33 American Thoracic Society. What constitutes an adverse health effect of air pollution? Official statement of the American Thoracic Society. Am J Respir Crit Care Med 2000; 161: 665-673.

34 Balmes J, Becklake M, Blanc P, et al. American Thoracic Society Statement: occupational contribution to the burden of airway disease. Am J Respir Crit Care Med 2003; 167: 787-797.

35 Khaltaev N. WHO strategy for prevention and control of chronic obstructive pulmonary disease. Exp Lung Res 2005; 31: Suppl. 1, 55-56.

36 World Health Organization. WHO strategy for prevention and control of chronic respiratory diseases. World Health Organization Publications, 2001. www.who.int/respiratory/ publications/WHO_MNC_CRA_02.1.pdf. Date last accessed: December 2006.

37 World Health Organization. Implementation of the WHO strategy for prevention and control of chronic respiratory diseases. World Health Organization meeting report, Geneva, 2002. www.who.int/respiratory/publications/ WHO_MNC_CRA_02.2.pdf. Date last accessed: December 2006.

38 World Health Organization. Prevention and control of chronic respiratory diseases in low and middle-income African countries: a preliminary report. World Health Organization meeting report, Geneva, 2004.

39 World Health Organization. Prevention and control of chronic respiratory diseases at country level: towards a Global Alliance against Chronic Respiratory Diseases. World Health Organization meeting report, Geneva, 2005. www.who.int/respiratory/publications/WHO_NMH_ CHP_CPM_CRA_05.1.pdf. Date last accessed: December 2006.

40 Epping-Jordan JE, Galea G, Tukuitonga C, Beaglehole R. Preventing chronic diseases: taking stepwise action. Lancet 2005; 366: 1667-1671.

41 Haahtela T, Klaukka T, Koskela K, Erhola M, Laitinen LA. Asthma programme in Finland: a community problem needs community solutions. Thorax 2001; 56: 806-814.

42 ten Asbroek AH, Delnoij DM, Niessen LW, et al. Implementing global knowledge in local practice: a WHO lung health initiative in Nepal. Health Policy Plan 2005; 20: 290-301.

43 Billo NE. Do we need an asthma drug facility? Int J Tuberc Lung Dis 2004; 8: 391. 